\title{
Percepción de las instituciones formales e informales en la formación ciudadana de las Niñas y los
}

Perception of formal and informal institutions involved in the civic education of children

Moncerrat, Arango-Morales ${ }^{1}$

Universidad Autónoma de Nuevo León

DOI: http://doi.org/10.29105//pgc4.7-6

https://orcid.org/0000-0002-8399-8448

\section{RESUMEN}

El presente artículo es producto de una investigación, cuyo objetivo consistió en determinar si las niñas y niños de 10 a 12 años de los municipios de Monterrey y Guadalupe Nuevo León, perciben el valor libertad de expresión necesario para coadyuvar en la formación ciudadana, en la institución informal televisión. Se aplicó el método mixto, descriptivo, exploratorio, transversal a través de la técnica la encuesta. Tras la aplicación de los cuestionarios a una muestra de 384 niños y niñas, se encontró que: las niñas y los niños perciben que sus personajes televisivos favoritos manifiestan uno de los valores necesarios en la formación ciudadana, la libertad de expresión. Los menores expresan sus ideas, utilizando para ello, la comunicación tanto verbal como no verbal, pero también utiliza acciones como: insultando y ofendiendo a los demás personajes. Se concluye que la escuela y la televisión son instituciones formales e informales que contribuyen a la formación ciudadana de las niñas y los niños, estas desempeñan un papel fundamental como formadores de opinión, por lo que son determinantes para lograr una sociedad más equitativa que ayude a crear un capital activo para el mantenimiento del orden, las costumbres y tradiciones de México.

Palabras clave: Formación Ciudadana, Libertad, Menores, Instituciones Formales e Informales y Televisión.

\section{ABSTRACT}

This article is the product of an investigation, which objective was to determine whether girls and boys from 10 to 12 years of age in the municipalities of Monterrey and Guadalupe Nuevo León, perceive the value of freedom of expression necessary to contribute to citizen training, in the informal television institution. The mixed, descriptive, exploratory, cross-sectional method was applied through the survey technique. After applying the questionnaires to a sample of 384 boys and girls, it was found that: girls and boys perceive that their favorite television characters manifest one of the necessary values in citizen training, freedom of expression. Children express their ideas, using both verbal and non-verbal communication, but also use actions such as: insulting and offending other characters. It is concluded that school and television are formal and informal institutions that contribute to the civic education of girls and boys; they play a fundamental role as opinion makers, and are therefore decisive in achieving a more equitable society that helps create an active capital for the maintenance of order, customs and traditions of Mexico.

Key words: Citizen Education, Liberty, Smaller, Formal and Informal Institutions, Televisión.

Cómo referenciar este artículo:

Arango Morales, M. (2018). Percepción de las instituciones formales e informales en la formación ciudadana de las Niñas y los Niños. Revista Política, Globalidad y Ciudadanía, 82-94. Recuperado de http://revpoliticas.uanl.mx/ index.php/RPGyC/article/view/159

Recibido: 20 de Agosto 2017 - Aceptado: 30 de Octubre 2017

\section{(c) BY-NC-ND}

1 Doctora en Filosofía con orientación en Ciencias Política por la Universidad Autónoma de nuevo León. Coordinadora de la Facultad de Ciencias de la Comunicación de la Universidad Autónoma de nuevo León. Email: monserrat.arangom@uanl.mx

Revista Política, Globalidad y Ciudadanía, Vol. 4 No. 7, Enero - Junio 2018, Universidad Autónoma de Nuevo León, Monterrey, México, ISSN 2395-8448. pp 82-94. http://revpoliticas.uanl.mx/index.php/RPGyC/article/view/159 


\section{INTRODUCCIÓN}

La Formación Ciudadana se inicia de manera informal en la familia, a través del ejemplo de acciones y actitudes de los padres, y de manera formal en la escuela a través de materias relativas a la educación cívica, de esta manera, los futuros ciudadanos estarán mas preparados y comprometidos con el bien común, ya que la consolidación de una ciudadanía solo puede darse a través de la educación, y si esta es desarrollada desde la infancia dentro de los espacios educativo formales e informales, los menores adquirirán valores cívicos que podrán ser interiorizados y desarrollados a plenitud en su desenvolvimiento en sociedad.

Los menores de edad se desenvuelven de manera natural a través de distintos factores, como edad, el conocimiento, la convivencia y por su puesto la televisión, respecto a ellos Oliva y Castro (2012) apuntan que actualmente el proceso educativo se encuentra rebasado por el avance tecnológico, y que si bien aún no se encuentra generalizado es previsible pensar que pronto cubrirá todo los espacios, igual que ocurrió con la televisión y cuya presencia se encuentra en casi todos los hogares mexicana.

Sobre lo anterior, es importante señalar que componentes como la educación, la cultura política y la participación ciudadana son aspectos ligados a los asuntos públicos, y que "son atributos sociales que pueden contribuir a que la incipiente democracia mexicana alcance mejores estadios de calidad" (Téllez y González, 2013, p. 102).

La instituciones formales como la escuela y las informales como la televisión, son elementos necesarios para lograr que los niños que serán los futuros ciudadanos tengan una educación en las cuestiones de la comunidad y puedan tener mayor participación en los asuntos públicos, por ello, es necesario que se desarrollen desde temprana edad los valores democráticos, ya que si estos se interiorizan profundamente, el régimen alcanza estabilidad y su respuesta es socialmente eficiente (Téllez y González, 2013, p. 98).

Por tanto, la disposición hacia la democracia es producto del aprendizaje social, y de ahí se deriva la importancia de la influencia en la interiorización de las normas que son las que establecen las libertades individuales y la adhesión a los principios democráticos (Corvera, 2010), de esta manera, la ciudadanía precisa del desarrollo de las capacidades individuales para que se puedan ejercer los derechos, y la institución académica aparece como el principal factor que los gobiernos tienen para educar a los futuros ciudadanos.

Bajo esta mirada, la primera competencia que se le presenta a la institución educativa en la adquisición de valores, es la Televisión; esta herramienta transmite normas o las contradice, presentan valores o antivalores, pero de cualquier manera contribuye a forjar una determinada visión del mundo. La televisión es una herramienta que también educa, aunque ésta educación no sea lo que se espera. La Televisión llegó para quedarse ya que forma parte de la cotidianidad de la vida familiar y no solo de las familias urbanas sino también de las urbanas.

El contexto actual del desarrollo de las niñas, niños y adolescentes están experimentando cambios importantes en la construcción de su identidad, por ello, la Televisión adquiere importancia, porque trata aspectos socio morales que generan que los menores se identifiquen con ciertos programas y personajes, que generan concepciones de vida y prejuicios, entre otros, este medio de comunicación, aumenta la posibilidad de socialización cuando sus "contenidos responden a expectativas, necesidades o intereses previos del grupo de referencia" (Medrano y Airbe, 2008, p. 54).

Es por ello, que la educación es el factor más importante a la hora de empoderar a los futuros ciudadanos, y es que fuera del contexto escolar es complicado transmitir a los menores valores cívicos. Aún así, evidentemente, hay que aprovechar también la educación no formal, como los medios masivos de comunicación (Ferrete, 2011).

Revista Política, Globalidad y Ciudadanía, Vol. 4 No. 7, Enero - Junio 2018, Universidad Autónoma de Nuevo León, Monterrey, México, ISSN 2395-8448. pp 82-94. http://revpoliticas.uanl.mx/index.php/RPGyC/article/view/159 


\section{FUNDAMENTO TEÓRICO}

\section{Instituciones Formales e informales en la formación ciudadana de los menores}

La ciencia política sienta sus raíces en el estudio de las instituciones, teorías como el conductismo y la elección racional argumentan que los individuos no se ven obligados por las instituciones formales o informales a tomar elecciones, sin embargo existen estudios que demuestran que instituciones como la Televisión influyen en los infantes al ser un sector vulnerable y exponerse de tres a cuatro horas diarias a ella (Aldea, 2004; Cerda, 2009; Lazo, 2005), y que pueden ser influenciados a construir su propia perspectiva del mundo, creando una visión falsa de la realidad.

Sobre esta influencia y desde la perspectiva de Guy Peters (2003) la formación de las instituciones públicas da inicio debido a la necesidad de orientar el comportamiento inestable de los individuos y por la necesidad de orientarlos hacia un bien común, estas instituciones han sido definidas por Scott (citado en Guy Peters, 2003) como: “ estructuras y actividades cognitivas, normativas y reguladoras que brindan estabilidad y significado al comportamiento social (p.159). Esta estabilidad se debe a la versión de la actividad reguladora del Institucionalismo que se apoya en las reglas para definir las instituciones; este enfoque tiene como razón regular el comportamiento de la sociedad, por lo que las reglas, van a las Instituciones y estas a su vez serán un medio a través de la cual se influirá sobre los individuos.

Tomando como base la información expuesta, se asume que las instituciones son sistemas que regulan las conductas tanto individuales como colectivas, y estas tienen sin duda como primer referente los valores que se adquieren en el transcurso de la vida y han sido interiorizados mediante la repetición de las acciones, de ahí la importancia de la socialización con las instituciones por parte de los menores.

Respecto a estos valores, Frondizi (1945, citado en Uvalle Berrones R., 2011) postula que tanto en la concepción como en la funcionalidad de la sociedad, los valores son referentes obligados dado que en términos de gobierno, son inherentes para su estructuración, vigencia y funcionalidad, alguno de ellos son: el bienestar, equidad, desarrollo, igualdad, justicia y calidad de vida. Este mismo autor señala otros valores como: el civismo, civilidad, tolerancia y respeto, ya que son parte de la conducta de los actores (ciudadanos), las organizaciones e instituciones en diversos momentos del quehacer colectivo. Por tanto, se asume que las instituciones se ven influenciadas por los valores que cada individuo trae consigo.

Para este trabajo, una de las organizaciones institucionales informales más importantes es la de la industria del entretenimiento, y de entre ellas: la Televisión. La Televisión como institución se relaciona con lo que es público y privado, y conceden importancia a las relaciones que establecen no solo con las personas sino también con organizaciones sociales, culturales, políticas y económicas en las sociedades modernas (Elizalde 2013). Douglas North (1993 citado en Elizalde 2013) asume que la Televisión es una institución, porque funciona como patrón y guía para la interacción humana y que esta interacciones son distintas en cada país, ya que las personas se encuentran condicionadas para actuar cada que cambian de sociedad aunque desarrollen acciones similares.

\section{La Televisión como Institución Informal}

La Televisión podría ser al mismo tiempo una organización y una institución. Una organización porque está conformada por el grupo de personas que la forman, que tienen objetivos que persiguen como organización y una forma de planeación, en tanto que la institución es el conjunto de reglas, normas sociales y valores que condicionan la conducta de esas personas para que desarrollen una acción ordenada (Douglas, 1993, citado en Elizalde 2013). 
Por tanto, el personal que labora al interior de la institución Televisión, deben tener conocimiento de la Ley General de los Derechos de Niñas, Niños y Adolescentes y de la Ley Federal de Telecomunicaciones y Radiodifusión, para cumplir con su responsabilidad social, y generar contenidos aptos para los menores que contribuyan a su formación difundiendo información de conformidad con los objetivos de la educación.

Este conocimiento es importante debido a que laTelevisión y las nuevas tecnologías se relacionan con los Niños desde temprana edad, y dependiendo del tipo de formación educativa que cada sociedad practique, es el tipo de ciudadano que tendrá. La Televisión a través de las actividades lúdicas que llevan a cabo, realizan la socialización neesaria para que se interiorisen las costumbres y valores de la comunidad y los individuos aprenden a conducirse en ella. De acuerdo con los modelos teóricos de Bandura y Gerbner (Igartúa, 2008), los niños pueden aprender una gran cantidad de cosas sobre la vida social viendo televisión, puede modelar sus comportamientos y fomentar la interiorización de temas como: roles sexuales, ancianos, las profesiones, los tipos de familia, las minorías étnicas e inmigrantes entre otros.

Tomando en cuenta que el objeto de estudio de este trabajo de investigación son las y los niños de 10 a 12 años, que se encuentran en una etapa en la que están construyendo su identidad, y donde adquieren categorías fundamentales de evaluación y juicio (Lagroye, 1994), se presenta como importante conocer cuáles son sus programas y personajes favoritos para conocer que es lo que los menores están consumiendo. Dada la etapa en la que se encuentran y que tienen acceso ilimitado a la televisión, probablemente se encontrarían frente a mensajes opuestos a los aprendidos en la familia y la escuela, y ello podría reforzar y perturbar sus creencias o actitudes sobre temas en los que necesitan ser guiados por padres o maestros.

La Televisión, tanto en su sistema de señal abierta como de paga, se consideran factores que generan socialización, ya que cumplen un papel decisivo en la conservación de opiniones y cuyo efecto principal es consolidar las representaciones de diversos temas, entre ellos los políticos (Lagroye ,1994), este autor argumenta que estas creencias son analizadas por los diversos receptores y recibidas de manera selectiva por los individuos, desde esta mirada, el rol de la familia sigue siendo fundamental en el desarrollo ciudadano de los menores, ya que es en este espacio, donde los menores escuchan los comentarios de los adultos referente a la vida política de la sociedad, y es en la familia donde se encuentra la herramienta Televisión y en esta socialización, se exponen diversas opiniones, que "sirven para conservar y reforzar las opiniones preexistentes" (Lagroye, 1994, p. 400).

\section{La Televisión en la formación de valores}

Los valores se manifiestan como referentes de funcionalidad de una sociedad y los contextos que ayudan a su adquisición se presentan como importantes de investigar, ya que estos generan conductas que son el resultado de dicha influencia (Instituto Federal Electoral, 2000). Uno de estos contextos con los que el Niño tiene contacto directo y en algunas ocasiones sin supervisión de la familia, es la Televisión. Sobre el contenido de esta herramienta es que se establece un análisis respecto a su contribución en la formación de valores.

La Televisión como institución, exponen valores que son importantes para ésta investigación, por ello, el concepto valor lo entenderemos como los principios que nos permiten orientar nuestro comportamiento a fin de realizarnos como individuos y que reflejan nuestros intereses, sentimientos y convicciones, siendo además la base para vivir en comunidad y relacionarnos con las demás personas, permitiéndonos regular nuestra conducta para el bienestar colectivo y tener de esta manera una convivencia armoniosa (Jiménez J. C., 2008).

Por tanto, la crisis en la formación de los valores solo es posible modificarla a través de instituciones estructuradas y bien organizadas como la familia, pero, como ya se ha indicado anteriormente, los menores

Revista Política, Globalidad y Ciudadanía, Vol. 4 No. 7, Enero - Junio 2018, Universidad Autónoma de Nuevo León, Monterrey, México, ISSN 2395-8448. pp 82-94. http://revpoliticas.uanl.mx/index.php/RPGyC/article/view/159 
están recibiendo aprendizaje no solo por medio de la institución educativa formal (escuela) sino también a través de la televisión con la que los niños tienen constante contacto y que también es una herramienta que proporciona aprendizaje. Este instrumento tecnológico cumple un doble papel, por una parte su actividad es vital para el desarrollo económico de cualquier país y por otra, hacen realidad los derechos fundamentales de las personas, a través de la libertad de expresión (Unión, 2012).

Otros aspectos formadores de valores como conductas, actitudes y expresiones verbales y no verbales que se repiten, pueden ser tomadas por los infantes como un conocimiento común, por lo que resulta necesario analizar la calidad de los contenidos de programas televisivos consumidos por la niñez, ya que el lenguaje que se encuentra en los contenidos audiovisuales, es un fuerte estímulo en su relación con los medios que genera influencia en su capacidad lingüística (Fernández y Ma DoloresTur Viñes, 2005).

De esta manera, y aunque estos trabajos exponen datos que manifiestan que los programas contienen mensajes auditivos y visuales negativos, existen otras opiniones que afirman que la Televisión por sí solo no enseña nada, que para que pueda realmente tener efecto sobre los menores, es necesario que los niños se conecten con sus propias experiencias e ideas a los mensajes que se transmiten (Alonso, Mantilla y Vázquez, 1995, en Digón Regueiro, 2008).

Respecto a la emisión de estaciones televisivas, el Estado de Nuevo León recibe señal abierta de las siguientes televisoras: Televisa (10 y 5); Televisión Azteca(13 y 7); Canal Once (Instituto Politécnico Nacional); Canal 40 (Propiedad de Televisora del Valle de México y sus contenidos son producidos por Televisión Azteca); Canal 22 (Televisión de la República Mexicana (TRM TV UNAM (Universidad Nacional Autónoma de México (UNAM) en sinergia con la Dirección General de Televisión Educativa (DGTVE), responsable de la red de señal satelital educativa EDUSAT); Canal 12(Multimedios Estrellas de Oro); Radio y Televisión de Nuevo León; Canal 53 (Universidad Autónoma de Nuevo León).

Cada una de estas 11 estaciones televisivas cuenta con una programación que genera entretenimiento e información para diferentes públicos, mucha de ella generada para una cultura diferente. El canal once del IPN, lanzó el 24 de agosto de 2015, una barra infantil, que inicia sus transmisiones de lunes a viernes de ocho y media de la mañana a cinco de la tarde; sábado de ocho a doce del mediodía y los domingo de ocho a una de la tarde, sin embargo, los contenidos siguen siendo extranjeros.

Respecto a los contenidos, Abelman y Atkin (2000, citados en Igartua, 2008) realizaron un estudio con una muestra de 700 niños de entre 7 y 12 años, con la que buscaban demostrar los principales motivos por los que los menores se exponían a la Televisión, en donde se determinaron cinco factores principales: a) pasar el tiempo o por habito, b) búsqueda de entretenimiento, c) información, d) compañía y e) escape. Además comprobaron que los niños que observaban en mayor cantidad la televisión son aquellos que buscan: entretenimiento, el hábito y el escape, mientras que los niños que buscaban en la televisión información y compañía mostraban un menor nivel de consumo televisivo.

\section{Formación ciudadana en las Niñas y los Niños}

Para efecto de este trabajo de investigación, el concepto de ciudadanía, será tomado del Instituto Nacional Electoral (INE, 2007) quién manifiesta que el término representa una relación entre el individuo y el Estado como consecuencia de una serie de derechos y obligaciones. Con ello se entiende que un ciudadano es miembro de una comunidad política y que al igual que los otros miembros de ella, tiene derechos y obligaciones.

Dentro de la comunidad y en un sistema político democrático, el argumento principal de acción depende no solo de sus estructuras básicas sino también de las cualidades y actitudes de los ciudadanos, de ahí que

Revista Política, Globalidad y Ciudadanía, Vol. 4 No. 7, Enero - Junio 2018, Universidad Autónoma de Nuevo León, Monterrey, México, ISSN 2395-8448. pp. 82-94. http://revpoliticas.uanl.mx/index.php/RPGyC/article/view/159 
la relación entre democracia y educación sean indisolubles. Por tanto, el sistema político no puede desentenderse de la educación de los individuos ya que es el responsable de que los sujetos estén interesados en la cosa pública (Corvera, 2010).

Weber (citado en Corvera, 2010) afirmaba que todo hombre es producto de la estructura social de su época y que él mismo contribuye a modelarlas y cambiarlas. Visto de esta manera, la calidad de los ciudadanos es una condición dentro del Estado que alude a sus derechos, y a los que los individuos tienen acceso por el hecho mismo de ser ciudadanos de una nación y por haber cumplido la edad requerida, esta calidad también dependerá de los procesos de formación ciudadana que le proporcionan al ciudadano las competencias para vivir en la democracia.

Hablar de ciudadanía implica entenderla -como se expresó en el Consejo Europeo en el 2000 y publicado en el Measuring Active Citizenship -como un medio que empodera a los ciudadanos con el objeto de que tengan voz en su comunidad, un sentimiento de pertenencia a ella, valorar la democracia y comprender la diferencia con otras culturas (Hoskins et al., 2006 citado en IFE, 2014). El ejercicio de esta ciudadanía en un gobierno democrático implica que debe existir un sistema legal que garantice los mismos derechos e igualdades para todos los ciudadanos (IFE, 2014), en este sentido el Estado de Derecho resulta notable en la protección de los ciudadanos.

En la actualidad, la democracia es considerada como la mejor forma de gobierno y organización de la vida social, sin embargo, Aguilera (2008) apunta que esta forma de gobierno se expone como muy fragil y vulnerable ya que depende fundamentalmente de la consolidación institucional del Estado de Derecho y una sólida ética alcanzada a través de una educación ético-cívica. Tomando esto como base, se puede argumentar que una de las finalidadades de la educación, es lograr una comunidad reforzada en valores como la justicia, el respeto y la igualdad de género entre otros (Aguilera, 2008).

\section{La libertad como valor ciudadano}

Las sociedades democráticas modernas se caracterizan por su multiculturalidad y pluralidad de ideas, en ellas, es posible visibilizar diversos valores, entre los que podemos mencionar: la Libertad, la Igualdad y la Tolerancia. Dichos valores, son elementos necesarios para generar la formación ciudadana, así como son precisos en la construcción de un gobierno democrático, y constituyen además tres factores elementales para la convivencia en comunidad.

Esta convivencia nos remite a la noción de Libertad, y al de la acción libre de los hombres, determinando la necesidad de ella en términos de decidir no solo sobre lo dado sino sobre lo posible, teniendo además como misión y fin, el de "asegurar la vida en el sentido más amplio" (Arendt citada en Sánchez, 2008, p.13), hacer esto, es hacer posible que el individuo persiga sus fines en términos de paz y tranquilidad y que permita además convivir con otros en una organización política.

Como consecuencia de esta convivencia, se debe tomar conciencia de la Libertad en la medida en que se realiza mediante contacto con los demás, y no en términos de una Libertad interior, ya que la Libertad es entendida como un status del hombre libre, que le permite de forma física, desplazarse de un lado a otro y encontrarse con otros individuos utilizando para comunicarse la acción y la palabra (Benítez, 2008).

Así mismo, la Libertad no puede manifestarse separando los derechos y deberes individuales de los colectivos, ya que una comunidad depende del sentido comunitario de sus ciudadanos y los deberes individuales que están relacionados con los colectivos en la búsqueda de proyectos en común y sobre los que deben dedicar buena parte de sus esfuerzos y recursos (Thesing, 1999). Por ello, la Libertad debiera ser vista como un factor que permite la asimilación e interiorización de valores que expone el individuo como

Revista Política, Globalidad y Ciudadanía, Vol. 4 No. 7, Enero - Junio 2018, Universidad Autónoma de Nuevo León, Monterrey,

México, ISSN 2395-8448. pp 82-94. http://revpoliticas.uanl.mx/index.php/RPGyC/article/view/159 
ser individual y que al mismo tiempo los expone como ciudadanos, ya que solo de esta manera se lograría la unificación de los valores en aras de lograr un beneficio para todos los ciudadanos.

Es por ello que una democracia requiere que sus ciudadanos sean autónomos, críticos y reflexivos, capaces de generar una participación e integración de proyectos en común (Aguilera, 2010), y esto solo se logra mediante la educación de los futuros ciudadanos. Esta educación formal e informal debe fundamentarse en el reconocimiento de los derechos de libertad -sin la protección de esos derechos la democracia sería imposible-ya que se presenta como inconcebible pensar que a los individuos se les prohibiera ejercer su derecho a la elección (Woldenberg, 2007). Esta libertad a la elección debe ser aprendida desde la infancia, ya que es durante esta etapa que se adquieren las evaluaciones y juicios, constituyéndose también las actitudes que forman las creencias (Lagroye, 1994).

Si es durante la infancia que los menores aprenden a ejercer la elección es donde mayor cuidado se debe tener, sobre todo en la supervisión de los programas que consumen, así como las redes sociales a las que tienen acceso y las personas con las que se conectan por parte de los padres, ya que son los menores quienes eligen lo que más los satisface, los que los mantienen entretenidos, y bajo esta mirada, los menores pueden aprender observando caricaturas, películas y programas unitarios de Televisión, que la violencia es un concepto que puede generar risas, porque en ellos se generan imágenes donde los personajes pueden ser lastimados de diversas formas y siempre resulta divertido sin que exista una reacción (castigo) frente al evento. Programas con este tipo de contenidos, representan un problema para la Formación Ciudadana, ya que los niños construyen su personalidad al identificarse con acciones, actitudes y lenguajes con los que tiene constante contacto.

La Televisión es una herramienta que se encuentra presente en cada hogar como un instrumento que genera entretenimiento, los niños se encuentran en constante contacto con ella, y es a través de su observancia que puede descubrir normas y creencias con el objeto de asimilarlas y más adelante reproducirlas en su conducta en relación con sus pares. Lagroye (1994) señala que el Niño trata de observar actividades que podrían considerarse como normales por parte de quienes lo rodean, familia, pares, escuela y los medios masivos de comunicación (MMC); trata de aprender aunque sea de forma confusa las creencias que se encuentren acorde con esas actitudes sobre la base de la repetición. Si a través de los MMC, los niños escuchan las noticias y las reafirman con los comentarios de su familia, implica valoraciones de actitudes frente al poder (padres). Por tanto, aprenderá de acuerdo a las acciones realizadas por el Estado, que vive en una sociedad democrática o no (Lagroye, 1994).

\section{MÉTODO}

\section{Diseño}

El presente estudio tuvo como Objetivo realizar un trabajo exploratorio que generara evidencia respecto de la percepción que las Niñas y los Niños de 10 a 12 de los municipios de Monterrey y Guadalupe, Nuevo León, tienen de sus programas y personajes televisivos favoritos. El método seleccionado es cuantitativo, de donde el instrumento de medición es el cuestionario. Esta herramienta consiste en un conjunto de preguntas respecto a las variables que se van a medir y su contenido estuvo conformado por preguntas cerradas y abiertas.

\section{Participantes}

Conforme a datos del INEGI (2010), en Nuevo León se contaba con una población de 4,653, 458 Individuos. La población objeto de este estudio, Niñas y Niños con edades entre los 10 y los 12 años, resultaron en un total de 92, 562, por lo que la muestra representativa, se calculó en 384 que viven en los municipios de Monterrey y Guadalupe NL. Aplicándose una muestra real de 500 cuestionarios. Se obtuvo una muestra no probabilística ya que la selección fue referida por las y los directores de las escuelas primarias públicas,

Revista Política, Globalidad y Ciudadanía, Vol. 4 No. 7, Enero - Junio 2018, Universidad Autónoma de Nuevo León, Monterrey, México, ISSN 2395-8448. pp. 82-94. http://revpoliticas.uanl.mx/index.php/RPGyC/article/view/159 
de dichos municipios, siendo quienes seleccionen los grupos a los que se les aplicó el cuestionario. Dicha selección se realizó al azar, ya que se consideró que en algunas escuelas se cuenta con dos y hasta con tres grupos de quinto y sexto año de primaria.

\section{Procedimiento}

Se utilizaron análisis no paramétricos, que se limitan a analizar las propiedades nominales de los datos $\mathrm{y}$, añaden el termino de distribución libre para referirse a los contrastes que no necesitan establecer supuestos sobre las poblaciones originales de las que se extrae la muestra (Hernández et al., 2006). A partir de la información proporcionada por la muestra, se podrá conocer cuál es el comportamiento de la población con un riesgo de error en términos de probabilidades. Este trabajo utilizó el sistema SPSS para realizar el análisis de los datos.

\section{RESULTADOS}

Los resultados generados a partir del análisis de los datos capturados de 500 cuestionarios en el sistema SPSS, en las que se aplicaron 33 reactivos (preguntas abiertas y cerradas ) y cuyo objeto de estudio son las Niñas y Niños de 10, 11 y 12 años de Monterrey y Guadalupe, Nuevo León, arrojaron información que permite determinar si las niñas y los niños perciben que sus personajes televisivos favoritos expresan libremente sus ideas y de que forma llevan a cabo la expresión de este valor. Además se buscó determinar si el valor señalado anteriormente es interiorizado a través de expresiones y actitudes que los menores realizan en su vida diaria.

Este trabajo de investigación inició por establecer cuál era el programa y el personaje favorito de las Niñas y los Niños, concluyendo que el programa de mayor preferencia de los menores de ambos sexos es Bob Esponja, coincidiendo este mismo personaje como el de mayor gusto. Con la obtención de estos datos, era necesarios determinar si los menores perciben que su personajes favoritos expresan sus ideas libremente.

Al preguntar a los Niños si el personaje favorito de su programa preferido expresaba libremente sus ideas y pensamientos, independientemente de lo que digan los otros personajes, el $88.2 \%(n=441)$ contesto que sí, mientras que el 11.8\% (n=59) respondió que no.

Tabla No. 1. Frecuencia

¿Tu personaje favorito expresa libremente sus ideas y pensamientos?

\begin{tabular}{|c|c|c|}
\hline & Frecuencia & Porcentaje \\
\hline $\mathrm{Si}$ & 441 & 88.2 \\
\hline $\mathrm{No}$ & 59 & 11.8 \\
\hline
\end{tabular}

Fuente: Elaboración propia. $\mathrm{N}=500$

Una vez establecido que los personajes favoritos expresan libremente sus ideas, lo siguiente era que señalaran que tanto espresan sus ideas y pensamientos, encontrandose los siguientes resultados:

Tabla No. 2. Frecuencia

¿Qué tanto expresa tu personaje favorito sus ideas y pensamientos?

\begin{tabular}{|c|c|c|}
\hline & Frecuencia & Porcentaje \\
\hline Mucho & 325 & 65.0 \\
\hline Poco & 163 & 32.6 \\
\hline Nada & 12 & 2.4 \\
\hline
\end{tabular}

Fuente: Elaboración propia. $\mathrm{N}=500$

Revista Política, Globalidad y Ciudadanía, Vol. 4 No. 7, Enero - Junio 2018, Universidad Autónoma de Nuevo León, Monterrey, México, ISSN 2395-8448. pp 82-94. http://revpoliticas.uanl.mx/index.php/RPGyC/article/view/159 
Los niños respondieron que mucho con $65.0 \%(\mathrm{n}=325)$, poco con $32.6 \%(\mathrm{n}=163)$ y nada con $2.4 \%$ $(\mathrm{n}=12)$. Si los personajes favoritos expresan sus ideas mucho, poco o nada, ahora era importante conocer las formas en que expresan sus ideas los personajes, encontrándose que los códigos arrojados fueron: comunicándose, con $47.4 \%(\mathrm{n}=237)$; con acciones positivas $17.4 \%(\mathrm{n}=87)$; divertida y emocionada con $15.0 \%$ $(\mathrm{n}=75)$; con acciones negativas con $7.4 \%(\mathrm{n}=37)$ y haciendo tonterías con $6.6 \%(\mathrm{n}=33)$.

Tabla No. 3

Tabla de contingencia ¿Tu personaje favorito expresa libremente sus ideas y pensamientos, independientemente de lo que digan los otros personajes? ¿Qué tanto expresa sus ideas?

\begin{tabular}{|c|c|c|}
\hline $\begin{array}{l}\text { ¿Tu personaje favorito expresa libremente sus ideas y } \\
\text { pensamientos, independientemente de lo que digan los otros } \\
\text { personajes? }\end{array}$ & \multicolumn{2}{|c|}{ ¿Qué tanto expresa sus ideas? } \\
\hline & Poco & Mucho \\
\hline No & $7.4 \%$ & $2.6 \%$ \\
\hline $\mathrm{Si}$ & $25.2 \%$ & $62.4 \%$ \\
\hline
\end{tabular}

Fuente: Elaboración propia. $\mathrm{N}=500$

El grupo muestra, afirmó con un $87.6 \%$ que sí; mientras que solo el $10.0 \%$ respondió que no y de hecho, los menores perciben que suelen expresar mucho sus ideas, con un $62.4 \%$ de los Niños así lo perciben; sin embargo, hay un $25.2 \%$ que cree que solo puede hacerlo poco. Estos datos arrojan información que describe que los menores perciben la Libertad de expresión en un gran porcentaje, lo cual es importante, porque demuestra que los infantes entienden la Libertad de un hombre respecto a otro (Espejel Mena, 2005).

Esta percepción se expone como vital ya que según Lagroye, (1994) la Libertad a la elección debe ser aprendida desde la infancia, ya que es durante esta etapa que se adquieren las evaluaciones y juicios, constituyéndose también las actitudes que forman las creencias. Este valor debe ser conocido y reafirmado en los futuros ciudadanos si es que se quiere que formen parte de una sociedad en términos de expresarse libremente y toma de decisiones, independientemente de si los individuos que los rodean estén de acuerdo o no con él.

Una vez definido que los menores perciben que el valor Libertad es expresado por su personaje favorito, el siguiente objetivo específico era identificar la forma en que esa Libertad era expresada por el personaje favorito, del programa de mayor audiencia de las Niñas y los Niños.

Tabla No. 4. Frecuencia

¿En qué forma expresa sus ideas el personaje?

\begin{tabular}{|l|c|c|}
\hline & Frecuencia & Porcentaje \\
\hline Comunicándose & 237 & 47.4 \\
\hline Con acciones positivas & 87 & 17.4 \\
\hline Divertida y emocionada & 75 & 15.0 \\
\hline Con acciones negativas & 37 & 7.4 \\
\hline Haciendo tonterías & 33 & 6.6 \\
\hline No expresa sus ideas & 15 & 3.0 \\
\hline No sabe & 7 & 1.4 \\
\hline
\end{tabular}

Fuente: Elaboración propia. $\mathrm{N}=500$

Revista Política, Globalidad y Ciudadanía, Vol. 4 No. 7, Enero - Junio 2018, Universidad Autónoma de Nuevo León, Monterrey, México, ISSN 2395-8448. pp. 82-94. http://revpoliticas.uanl.mx/index.php/RPGyC/article/view/159 
La tabla arroja datos que exponen que los menores perciben que sus personajes favoritos, utilizan la comunicación para expresar sus ideas independientemente de lo que piensen los demás. Se expone que la acción más recurrente es: a) comunicándose con $47.4 \%(\mathrm{n}=237)$ cuyo código significa: lo hace libremente, de manera inteligente, seria, respetuosa y directa; seguido de b) con acciones positivas con $17.4 \%(n=87)$ que significa: canta, baila, construye, ayuda a los demás, aconseja; además, c) de manera divertida y emocionada con $15.0 \%(\mathrm{n}=75)$, que se interpreta como: juega, ríe, se pone alegre, bromea; acciones negativas con $7.4 \%(n=37)$ que significa: peleándose, insultando, agrediendo verbalmente, hace lo que quiere y se burla.

Este trabajo de investigación determinó la forma es que los personajes favoritos de los menores expresan la libertad de expresión, y como ya se mostró anteriormente, lo hacen a través de la comunicación verbal y no verbal entre otras, y si la comunicación y las acciones positivas son factores relevantes en la expresión de las ideas, entonces se presenta como importante conocer cómo perciben los menores, el Respeto de los personajes a las ideas de los demás.

Tabla No. 5

Tabla de contingencia ¿Qué tanto consideras que tu personaje favorito respeta las ideas de los demás personajes? Sexo del entrevistado

\begin{tabular}{|c|c|c|c|}
\hline $\begin{array}{c}\text { Qué tanto consideras que tu personaje favorito } \\
\text { respeta las ideas de los demás personajes? }\end{array}$ & Hombre & Mujer & Total \\
\hline \multirow{2}{*}{ Mucho } & 131 & 160 & 291 \\
\cline { 2 - 4 } & $26.2 \%$ & $32.0 \%$ & $58.2 \%$ \\
\hline \multirow{2}{*}{ Poco } & 100 & 92 & 192 \\
\cline { 2 - 4 } & $20.0 \%$ & $18.4 \%$ & $38.4 \%$ \\
\hline
\end{tabular}

Fuente: Elaboración propia. $\mathrm{N}=500$

Sobre el valor Respeto, se encontró que es percibido por ambos sexos como que sí se respetan mucho las ideas de los otros $58.2 \%$ ( $\mathrm{n}=291$; y en un comparativo, el sistema arrojó datos que muestran que las mujeres perciben que si se respetan mucho las ideas con un 32.0\% ( $\mathrm{n}=160)$; mientras que los hombres perciben que se respetan mucho con $26.2 \%(\mathrm{n}=131)$. De forma general, el $58.2 \%$ de los menores perciben que no tienen una verdad absoluta y por lo tanto pueden aprender a solucionar los conflictos que se les presenten utilizando la comunicación para llegar a puntos de acuerdo, escuchando siempre la opinión de los demás.

La LFTYR (2014) manifiesta que las Niñas y los Niños aprenden a crearse una valoración interna, que les permite aprender que sus acciones físicas, personalidad y capacidades, serán evaluadas en función de ciertos estándares y que por lo tanto podrían ser sujetos de la aprobación de sus pares o incluso ser rechazados, por ello, siguen las acciones que la mayoría realiza y están pendientes de lo que necesitan hacer o tener para seguir perteneciendo a un grupo, ya que esta pertenencia les otorga protección y seguridad.

En nuestra sociedad los individuos se relacionan con otros a fin de lograr sus metas, como consecuencia de esta convivencia, toman conciencia de los límites de su libertad ya que esta es entendida como un status mediante la cual puede desplazarse de un lado a otro y encontrarse con otros individuos utilizando la palabra para expresar sus ideas. Esta valoración puede demostrar que los menores están conscientes de la importancia de la toma de decisiones y de la libertad de expresión, en la realización de actividades y convivencia en sociedad, en donde el diálogo y el respeto se presentan como variables básicas para el desarrollo del menor en sus relaciones de pares y familiares. 


\section{CONCLUSIONES}

El Objetivo General de este trabajo de investigación era determinar si el valor de la libertad de expresión se encontraba presente en el programa favorito de las Niñas y los Niños de 10 a 12 años de Monterrey y Guadalupe, NL., para lograr lo anterior, se les pregunto a los menores si su personaje favorito expresaba libremente sus ideas y pensamientos, independientemente de lo que digan los otros personajes.

Se concluye que las Niñas y los Niños perciben que los personajes favoritos expresan mucho sus ideas, utilizando para ello, la comunicación tanto verbal como no verbal, generando para ello expresiones como: diciendo lo que piensa, cantando, dialogando, hablando con familiares y amigos, incluso, con acciones como: insultando y ofendiendo a los demás personajes. Los datos muestran que los menores encuestados detectan que sus personajes favoritos expresan sus ideas en términos positivos, y que prefieren entablar ante todo un diálogo para expresar cuestiones con las que podrían no estar de acuerdo, y tratar a través de la comunicación establecer ideas y pensamientos para llegar a un disenso y de esta manera lograr acuerdos antes de generar posibles confrontaciones que terminarían en problemas.

La percepción de la Libertad de expresión, de los personajes favoritos, incluyen no solo acciones verbales, sino también no verbales, ya que también se comunican gesticulando con las manos y haciendo gestos con el rostro para atraer aún más la atención en los asuntos que tienen por compartir. Asimismo, dentro del código acciones positivas se detectó que tratan también de comunicar sus ideas a través de actividades artísticas como hacer dibujos, cantar, o bailar. Esto coincide con lo que Huizinga (2000) argumenta, las grandes ocupaciones de la convivencia humana están impregnadas de juego, y un ejemplo de ello es el lenguaje, primer instrumento de comunicación que el hombre creó para comunicarse, enseñar y mandar. Bajo esta mirada, los menores pueden aprender observando las gesticulaciones que sus personajes realizan, además de escuchar caricaturas, películas y programas unitarios de Televisión.

De esta manera, la comunicación en sus diferentes variables, siempre será una mejor opción por encima de la violencia, y aunque la violencia es un concepto que puede generar risas -porque en ellos se exponen imágenes donde los personajes pueden ser lastimados de diversas formas y en ocasiones se escuchan risas al final de cada acto- pueden ser capaces de entablar un diálogo para llegar a acuerdos mutuos sin generar actos violentos o imponer su opinión.

Lo anterior responde de manera afirmativa que los menores perciben que los personajes si manifiestan Libertad de expresión, tanto de manera positiva como negativa, probablemente por encontrarse en procesos de desarrollo donde el análisis de la situación se encuentra en vías de adquisición. Este trabajo también responde el objetivo de identificar si los menores detectan la forma en que se comunican. Queda expuesto que sus personajes favoritos expresan mucho sus ideas.

En las sociedad los individuos se relacionan con otros a fin de lograr sus metas, como consecuencia de esta convivencia, toman conciencia de los límites de su libertad ya que esta es entendida como un status mediante la cual puede desplazarse de un lado a otro y encontrarse con otros individuos utilizando la palabra para expresar sus ideas. Esta valoración puede demostrar que los menores están conscientes de la importancia de la toma de decisiones y de la libertad de expresión, en la realización de actividades y convivencia en sociedad, en donde el diálogo y el respeto se presentan como variables básicas para el desarrollo del menor en sus relaciones de pares y familiares. 


\section{REFERENCIAS}

Aguilera P. R. E. (2008). Ciudadanía democrática, educación política y comunidad en el pensamiento de John Dewey. En R. E. Portales, \& S. E. Nava, Pensamiento Político Contemporáneo Una Panorámica (pp.. 39-63). México: Porrúa

Benítez, R. S. (2008). Política, Pensamiento y Libertad en Hannah Arendt. En R. E. Navas, Pensamiento Político Contemporáneo (pp. 3-17). México: Porrúa.

Corvera, T. G. (Noviembre de 2010). Democracia y Formación Ciudadana. Recuperado el 14 de septiembre de 2014, de Colección Cuadernos de divulgación de la cultura democrática: http://www.ife.org.mx/ docs/IFE-v2/DECEYEC/EducacionCivica/CuadernosDivulgacion/CuadernosDivulgacion-pdfs/ CUAD_28.pdf

Digón Regueiro, P. (2008). Programación infantil y TV sensacionalista: entretener, desinformar, deseducar. Comunicar, 16, 65-76.

Elizalde L. (2013) Medios, instituciones y cambio institucional. El caso de la neo televisión. Recuperado de https://oteve.files.wordpress.com/2011/03/medios-instituciones-y-cambio-institucional-el-caso-dela-neotelevisic3b3n.pdf

Espejel Mena, J. \& Vega Vega, M. (2005). Libertad, igualdad y democracia liberal en el pensamiento de Norberto Bobbio. Redalyc, 77-91

Fernández Poyatos, M ${ }^{a}$ DoloresTur Viñes, Victoria. (2005). El mensaje televisivo de programas y publicidad dirigido al público infantil: aproximación a la calidad de su contenido. Comunicar, (025), pp. 1134-3478.

Ferrete S. C. (2011). Ciudadanía sin límites: El trasfondo de la gobernanza global. Quaderns de filosofia i ciència, 41, 2011, pp. 89-98

Universitat Jaume I Recuperado de http://roderic.uv.es/bitstream/handle/10550/43154/3976342. pdf? sequence $=1$

Huisinga J. (2008). Homo Ludens. España: Alianza editorial, S.A.

Igartua, J. (2008) La infancia construida: efectos prosociales y antisociales de los contenidos televisivos. España. Recuperado el 27/08/15 de: http://www.academia.edu/1586319/La_infancia_construida efectos_prosociales_y_antisociales_de_los_contenidos_televisivos 1

Instituto Federal Electoral, S. d. (2000). Derechos y Valores para la Niñez Mexicana. Mexico: Instituto Federal Electoral

Instituto Federal Electoral (2014). Informe país sobre la calidad de la ciudadanía en México. Recuperado de portalanterior.ine.mx/archivos2/s/DECEYEC/EducacionCivica/informe_pais_WEB-ok.pdf

Jiménez J.,C. (2008). El valor de los valores en las Organizaciones. Recuperado desde h t t p ; / w w w . elvalordelosvalores.com/definición/index/html

Lagroye J. (1994). Sociología Política. México: Fondo de Cultura Económica.

Medrano, Concepción: Airbe, Ana. (2008). Valores y contextos de desarrollo. Revista de Psicodidáctica, 13, pp. 53-67.

Oliva Z.LA. \& Castro C. (2012). Uso de la Televisión y su relación con los problemas de conducta. Alemania: Editorial académica española. 
Peters, G. (2003). El nuevo" institucionalismo. Teoría institucional en ciencia política. Recuperado de http://www.google.com.mx/url?url=http://www.revistas.unam.mx/index.php/rep/article/download/37 $650 / 34214 \& \mathrm{rct}=\mathrm{j} \& \mathrm{q}=\& \mathrm{esrc}=\mathrm{s} \& \mathrm{sa}=\mathrm{U} \& \mathrm{ved}=0$ ahUKEwiL9bGun5fXAhWJqFQKHVqpCJoQFggbMA I\&usg=AOvVaw1V49XeEAmVsZYseH-wur65

Sánchez B.R. ( 2008). Política, Pensamiento y Libertad en Hannah Arendt. En Aguilera $\quad$ P. $\quad$ RE $\quad$ \& Escamés N. S.(Ed.), Pensamiento Político Contemporáneo (pp..) México: Editorial Porrúa.

Téllez S. E; Y González M.S. (2013). Cultura y estructura política en guerrero. En Castillo D. JL; Mendieta R. A.; Coutiño O.F. (coord.), La realidad de la Comunicación Política relaciones de poder, actores y escenarios emergentes. México: Fontamara.

Thesing, J. (1999). Estado de Derecho y Democracia. Buenos Aires Argentina: Konrad Adenaver Stiftung.

Unión, C. d. (2012). Ley Federal de Radio y Televisión. Recuperado el 16 de agosto de 2014, de http:// www.diputados.gob.mx/LeyesBiblio/pdf/114.pdf.

Uvalle Berrones, R. (2011) Las ciencias sociales y las políticas públicas en el fortalecimiento del arte de gobernar convergencia. 18 (55) Universidad Autónoma del estado de México. Recuperado de http:// redalyc.uaemex.mx/src/inicio/ArtPdfRed.jsp?iCve

Woldenberg, J. (2007). El Cambio Democrático y la Educación Cívica en México. México, D.F.: Cal y Arena. 